\title{
Are people willing to pay to avoid health risks arising from land contamination? Evidence from housing values in Belgium
}

\author{
T. Thewys \& F. Clauw \\ Department of Economics and Law, Centre for Environmental Studies, \\ Limburg University Centre, Belgium.
}

\begin{abstract}
Soil pollution in residential areas coming from industrial activities can give rise to harmful health effects and extremely costly cleanup programs. In this paper, we try to establish a link between the monetized benefits of a potential soil reclamation program and the results of epidemiological research. From an economic point of view, we want to shift attention from cost-effectiveness principles of priority setting to a cost-benefit framework. We try to monetize the risks of potential health effects arising from a nearby pollution source by using a hedonic price model. We compare results available in the literature with a case study on the heavy metal contamination coming from a zinc smelter in LommelOverpelt (Belgium). A clear analogy is visible between the reduction in housing value and the harmful health effects of the cadmium pollution. Epidemiological research in this region showed that chronic exposure to cadmium pollution might promote skeletal demineralization, which might lead to increased bone fragility. We found that housing sale prices are decreasing in a nonlinear way with approximately $30 \%$ when approaching the site from a distance of 2.000 meters to the core of the pollution source.
\end{abstract}

\section{Introduction}

During several decennia, industrial activities have seriously polluted the environment where we live in. Air pollution and soil contamination are common problems to deal with in industrialized countries. Both give rise to harmful effects for people living in the neighbourhood of industrial sites. Damage to soil from modern human activities is still increasing. The major driving forces are 


\section{Environmental Health Risk}

population growth coupled with urbanization, agricultural intensification, industrial activities and transport. According to the European Environment Agency, it was estimated that there were approximately 1.500 .000 potentially contaminated sites in 1998. About 300.000 of them were identified. A part of them endanger the health of people living in the nearby areas, this as a result of releases of harmful substances to groundwater or surface waters, uptake by plants and direct contact with people (European Environment Agency, [1]).

Table 1 shows two confronting ways in which human risks arising from soil pollution can be assessed, i.e. a scientific risk approach and a social risk approach. Risk assessment is important since it forms the basis for priority setting in risk management. Ferguson et al [2] consider the scientific approach as a formal way to assess contamination risk, whereas the social approach tries to identify how the involved people perceive risk. The scientific research tries to identify the kind of polluting substances, pathways of pollution etc., by carrying out extensive site researches. In other words, risk is assessed in a formal way.

Table 1: $\quad$ Risk analysis.

\begin{tabular}{|c|c|c|c|}
\hline & \multicolumn{2}{|l|}{ Scientific risk approach } & Social risk approach \\
\hline \multirow[b]{2}{*}{$\begin{array}{l}\text { Ex } \\
\text { ante }\end{array}$} & Formal risk assessment & Economic risk assessment & Intuitive risk assessment \\
\hline & Site research & $\begin{array}{l}\text { 1. Cost-effectiveness analys } \\
\text { 2. Cost-benefit analysis } \\
\text { Hedonic price analysis } \\
\text { (indirect) } \\
\text { Revealed choice }\end{array}$ & $\begin{array}{l}\text { Sontingent valuation } \\
\text { (direct) } \\
\text { Stated choice }\end{array}$ \\
\hline $\begin{array}{l}\text { Ex } \\
\text { post }\end{array}$ & $\begin{array}{l}\text { Epidemiological } \\
\text { studies }\end{array}$ & $\begin{array}{c}\text { Willingness to Pay (WTP) } \\
\text { for a healthy environment }\end{array}$ & 4 \\
\hline
\end{tabular}

In Flanders, the "VLIER-humaan" model is (amongst others) used to assess risks. This model is comparable to other well-known models like HESP and CSoil. However, in these models the social risk assessment is limited or absent. On the other hand, the social risk approach relies on people's perceptions (intuitive risk assessment). 
The way economists try to deal with the risk problem is somewhere in between the two contrasting points of view. It tries to be formal, and therefore highly quantified, as well as based on human preferences. In other words, objective and subjective components are integrated to assess risk. Costeffectiveness analysis focuses only on the monetary costs to realize a prior preemptive physical goal, i.e. a certain quality level of the soil (Thewys [3]). This principle is very popular in Europe to make decisions with respect to risk management. Cost-benefit analysis relies on the monetary costs and estimates of the possible benefits to assess whether a remediation project can be approved because of economic reasons. Usually, monetizing the benefits is a difficult task. There are two big approaches for measuring environmental benefits in a monetary way: stated preference methods and revealed preference methods.

The revealed preference methods try to uncover individuals' willingness to pay for a given non-market good (clean soil) from the individuals' actual actions in the market (housing prices). The main method that is based on this technique is the hedonic price method. It is an indirect method, since it uses data from a related market to value changes in the specific good of interest. Housing prices reveal to some extent the willingness to pay to avoid health risks stemming from soil contamination. A healthier environment gives rise to higher real estate values. On the other hand, stated preference methods attempt to uncover individuals' willingness to pay for a change in environmental quality in a direct way. The contingent valuation method simply asks people what they would be willing to pay for a quality improvement of the soil. This method makes use of market survey techniques. However, the latter seems to be a less reliable method than hedonic pricing, since problems of opportunistic behaviour are hard to deal with. For this reason we will only elaborate on the hedonic price method.

Until now our assessment of pollution risk has only been done on an ex ante basis. People try to assess in monetary terms possible future health problems without being sure that these will become real, in their individual case. In general, consequences of pollution are usually gauged ex post by performing epidemiological studies. Contamination has to be there already for a particular amount of time before its impact on human health will be visible and measurable. However, identifying causal relationships between a specific pollution source and health problems is still a research area under development. Once results of epidemiological researches become available, it is possible to provide feedback to the already conducted economic analyses, which try to gauge human health risk ex ante.

\section{Benefits of soil reclamation}

\subsection{Monetizing benefits by hedonic price analysis}

The hedonic price method is a valuation method that is often used to value environmental goods. The valuation of these goods is a difficult task since there is no direct market for the environment as a 'good'. Nevertheless, it is possible to derive preferences for environmental goods in an indirect way. By using market transaction data it is possible to determine the willingness to pay for the 


\section{Environmental Health Risk}

remediation of polluted sites. However, nowadays the empirical applications of this method in the field of soil contamination are particularly limited to landfills (e.g. Thayer et al [4]) and toxic waste sites (e.g. Kohlhase [5]). Before proceeding, we explain shortly what this method is all about.

The hedonic price model was first introduced by Rosen [6], and since then this method has known many refinements, that are specifically situated in the empirical application of this model. The departure point of Rosen's model is the hypothesis that products are valued for their utility-bearing characteristics. In other words, consumers do not value composite commodities as a whole, but they value the characteristics, which those commodities embody. These composite commodities can be seen as bundles of characteristics. The purpose is to separate the effects of the various attributes of a good in such a way that can be gauged how changes in the levels of each characteristic affect utility. The price of a house reflects several attributes, which give a house its value. We distinguish structural characteristics (size of house, number of rooms, garage space, age of house, size of garden, etc.), local socio-economic and neighbourhood characteristics (quality of schools, unemployment rate, recreational facilities, racial composition, etc.) and environmental characteristics (noise, air pollution, soil pollution or proximity to any environmental amenity or disamenity). Each characteristic contributes to the consumer's overall utility of the good. Our specific point of interest is how a change in soil quality is reflected in these sales prices of houses. In this way, we would be able to monetize the benefits of possible soil remediation operations, i.e. measuring implicitly the value of health risk reduction in a preference based manner. People's behaviour in the housing market reveals the willingness to pay for a clean soil.

Specifically, we are interested in the benefits from the sanitation of a contaminated soil. A cost benefit analysis will then compare the benefits of a soil remediation operation with its costs. From an economic point of view, such a cost benefit analysis can be used to make a ranking between several polluted sites. By monetizing the benefits, we can use an economic rule to set priorities (Thewys and Clauw [7]).

\subsection{Link with health effects}

\subsubsection{Health effects from nearby landfills and industrial sites}

Landfills are an important pollution source that causes health and aesthetic problems when situated in the surroundings of residential areas (Lafère and Hens [8]). The possible health effects of living nearby a landfill make a lot of people unquiet, especially when the landfill contains hazardous chemical substances (e.g. heavy metals). Exposure can happen by different channels: contamination via groundwater dispersion, intake of contaminated food, air transported chemicals or substances via gas migration and in-house pollution by dust or evaporation of VOCs.

Dolk et al [9] show that there is a higher risk of congenital anomaly in babies whose mothers have residence near landfill sites that handle hazardous chemical wastes. However, the excess risk is small, but statistically significant. 
Nevertheless the question here remains open whether the effect is a causal one. Therefore a dose-response effect, in which the sites of highest hazard potential are associated with the highest risk of congenital anomaly, would give evidence for the hypothesis of a causal effect between risk of congenital anomaly and proximity to hazardous landfill sites.

Benedetti, Lavarone and Comba [10] review the available epidemiological studies on cancer risk associated with residence in the neighbourhood of industrial sites. They found clear evidence for an association between residential proximity to major industrial sites and risk of lung cancer and lymphohematopoietic malignancies. Moreover the hypothesis that the association is causal is gaining support from other epidemiological observations.

Nelen [11] shows a statistically significant difference between the study group and the control group in a recent research on soil contamination coming from a lead smelter in Hoboken (Antwerp, Belgium). Children between 1 and 12 years old, living in the district Moretusburg, were found to have higher lead concentrations in their blood than their counterparts living further away.

All these epidemiological studies have to deal with some important problems. First, there is a high degree of uncertainty about the level of exposure of the contamination to the surrounding neighbourhood. Therefore, it is difficult to gauge the dose-response effect between the contamination and health anomalies. Second, one has to be aware that the association between soil contamination and epidemiological consequences is complicated by several confounding factors, i.e. socio-economic status and personal habits. It is necessary to implement as many variables as possible in order to not distort the analysis. Third, most studies find an association between contamination and health effects. However, there is still a lot of uncertainty whether the relationship found is causal or not. In order to proof causality there is definitely a need for more data at a disaggregate level.

\subsubsection{Introduction of risk perception in hedonic price analysis}

The way risks are perceived by the public is of real importance in a revealed preference method like hedonic pricing. As already mentioned above, housing prices indirectly reveal people's preferences for a specific characteristic embodied in the house, e.g. a healthy and clean environment. However, it should be clear that people do not take into account real risk levels because of a lack of information and a high extent of uncertainty. In fact, it is the perception of the health risk stemming from the pollution source, which goes together with the evolution of housing prices. This perception is mainly built on information that is given by the media or politicians. Eventually it is possible that a large gap exists between real risks and perceived, just because of rumours.

The well-known fact that people usually overestimate low-probability events may suggest that perceived cancer risks from hazardous waste sites are higher than they really are. For this reason, Gayer, Hamilton and Viscusi [11] distinguish between the private values that residents place on risk reduction and those values that are expressed publicly in surveys. Indeed, by using market data instead of survey data, the authors are able to do their analysis with data that reveals the real preferences of the people. As a result, they also use a Bayesian 


\section{Environmental Health Risk}

learning process that is linked to a hedonic framework. In this case, the release of objective information lowers the perceived levels of risk.

\section{Empirical research}

\subsection{General results}

At the moment, several empirical applications of the hedonic price model have already been conducted, especially in the United States. Most of these studies try to monetize the harmful effects of living in the proximity of one or several landfills. Results of these studies differ with respect to the magnitude of the effect, but what is important is that the effects all point in the same direction, i.e. a reduction in value the closer the house is situated to the pollution source.

Table 2: $\quad$ Estimated willingness to pay.

\begin{tabular}{ccc}
\hline Distance from polluted site (in miles) & House price reduction (in \%) \\
\hline 1 & $12.8 \%$ \\
2 & $9.0 \%$ \\
3 & $5.2 \%$ \\
3.4 & $1.4 \%$ \\
\end{tabular}

Source: Brisson and Pearce [12]

Brisson and Pearce [12] conducted a meta-analysis, using 13 hedonic price studies (mainly American) to measure the effects of living in the neighbourhood of a landfill or a hazardous waste site. Table 2 reports the results of the estimated willingness to pay function. The regression analysis shows a declining effect with distance. The biggest effect, a house price reduction of $12 \%$, can be found in the immediate surroundings of the pollution source. Then the influence fades away slowly until approximately 3.4 miles from the site. At that distance, the pollution risk is no longer incorporated in the housing prices. In other words, house owners at 3.4 miles away from the polluted site are (on average) prepared to pay $12.8 \%$ more for a house with similar properties, this in order to avoid health risks coming from the pollution source. Otherwise stated, the willingness to accept the higher health risk is reflected in a housing price reduction of $12.8 \%$. 


\subsection{Case study for Flanders}

\subsubsection{Situation}

In the north-eastern part of Flanders, industrial zinc production already started in the second half of the 19th century. Around the site of an old zinc smelter, situated on the border of two communities, Lommel-Overpelt, serious land contamination, consisting of heavy metals, is a known problem. The population is well aware of the situation, all the more that government agencies distributed information about the pollution and issued restrictions on the use of vegetable gardens (Thewys et al [13]).

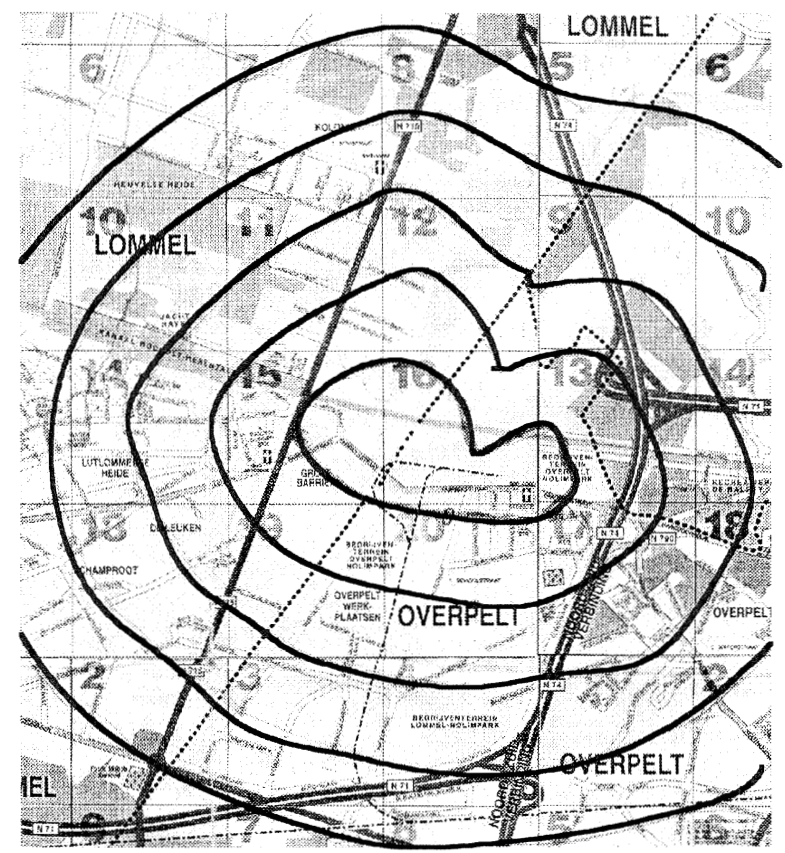

Figure 1. Cd contours in Lommel-Overpelt.

Data on Cd contamination (mg/kg dry soil) was collected by the CMK of the Limburg University Centre (period 1989-1993) and represented with contours on a map of the area, fig. 1 . The contamination is lower the further one is removed from the core pollution ( $12 \mathrm{mg} \mathrm{Cd} / \mathrm{kg}$ soil).

\subsubsection{Epidemiological research}

For the contaminated region, Staessen et al [14] conducted an epidemiological prospective population study of the environmental exposure to Cadmium. Therefore, data was used coming from urinary $\mathrm{Cd}$ excretion, $\mathrm{Cd}$ concentration 


\section{Environmental Health Risk}

levels in soil and in vegetables and data on the incidence of fractures (measured by bone density) and height loss.

The study concluded that "even at low degree of environmental exposure, cadmium may promote skeletal demineralisation, which may lead to increased bone fragility and raised risk of fractures'. It seems to be the case that the historical pollution in the region has an adverse effect on the studied health parameters. In the next section, we try to see whether this health risk is reflected in housing price differences.

\subsubsection{Willingness to pay to avoid health risks}

The hedonic price analysis about the benefits of an eventual land reclamation started from data on cadmium contamination $(\mathrm{mg} / \mathrm{kg}$ dry soil), represented with contours on a map of the area, fig. 1. Parallel with the contours indicating $\mathrm{Cd}$ concentrations of 12,6 and $3 \mathrm{mg} / \mathrm{kg}$, we designed contours indicating the distance from the 'core-pollution' $(12 \mathrm{mg} / \mathrm{kg} \mathrm{Cd})$ with regular intervals of 500 meters. These areas are indicated as 'zones'. After this marking out, all sales of residential houses were registered over the period 1989-1998 within a distance of 2500 meters from the core pollution. For these sales information was available about localisation, sales price, size (small, medium-sized, large, residence) of the house, surface of the parcel, number of rooms, garages, etc., maintenance condition, and comfort class (data provided by the regional Chambers of Notary). We gave each house a code according to the distance (zone) from the highest pollution area and according to whether the house was situated inside or outside the centre of the communities.

The estimated hedonic price equation, withholding only the significant variables, can be written as follows:

$$
\log \left(P_{i}\right)=b_{0}+b_{1} X_{i}+b_{2} X_{i}^{2}+b_{3} Y_{i}+b_{4} Z_{i}+e_{i}
$$

The dependent variable price is indicated by $P_{i}$. The independent variables are $X_{i}$ : the 'distance zone', $Y_{i}$ : the 'size of the house', and $Z_{i}$ : the 'surface' of the parcel. The log-quadratic specification allows for a degressive influence of the distance from the core pollution.

The estimated values for the coefficients $b_{i}$ are shown in table 3 . From this table we see that the 'distance zone' variable as indicator for the intensity of the risks emanating from the cadmium pollution, shows a coefficient significantly different from 0 at the $90 \%$ confidence level. 
Table 3: Regression results Houses site Lommel-Overpelt (eqn (1), only significant variables).

\begin{tabular}{|l|l|l|l|}
\hline & Independent variable & $\boldsymbol{b}_{\mathrm{i}}$ & $\mathbf{t}$-value \\
\hline$b_{0}$ & (Constant) & 13.690 & 59.6 \\
\hline$b_{1}$ & Distance zone & 0.298 & 2.2 \\
\hline$b_{2}$ & (Distance zone) $^{2}$ & -0.038 & -1.8 \\
\hline$b_{3}$ & Size of the house & 0.281 & 4.8 \\
\hline$b_{5}$ & Surface & 0.004 & 4.3 \\
\hline & $\mathrm{R}^{2}$ adjusted & 0.27 & \\
\hline & F-statistic & 16.35 & \\
\hline
\end{tabular}

Source: Thewys et al [13]

To fix the idea, one can deduce the marginal price of distance ( $M P D)$ from the estimated values of the coefficients $b_{1}$ and $b_{2}$ and using the average distance $\bar{X}$ and the average sales price $\bar{P}$ :

$M P D=\left(b_{1}+2 b_{2} \bar{X}\right) \bar{P}$.

As a result we come to an estimated price of distance of $€ 4.168$ per 500 meters (prices of 1998), being 5.3\% of the median sales price. Per zone of 500 meters further away from the polluted site, the real sales price for a comparable house increases with ca. $5 \%$. This effect is observed until a distance of 2.000 meters.

Applying these results on the number of houses (subdivided by size) in every zone, we arrive at an estimated loss of value in the range of $€ 20-23$ million. This amount can be considered as an estimation of the benefits of a clean up, being the removal of the loss of value of the real estate. It can be compared with the cost of different possible reclamation techniques. The benefit-cost ratio can be used in setting priorities in the governmental reclamation program.

Fig. 2 shows a summary of the above analysis, telling that $\mathrm{Cd}$ concentration levels, skeletal demineralization and property value reduction are increasing the closer one approaches the pollution source (the inner grey spot with $12 \mathrm{~kg} \mathrm{Cd} / \mathrm{kg}$ soil). Fig. 3 is a derived stylized representation of the property value reduction (in \%) around a hypothesized concentric pollution source. A point in the (X,Y) surface represents the position of a house with $\mathrm{X}$ and $\mathrm{Y}$ as coordinates. A health risk premium of approximately $30 \%$ is reflected in the housing prices in the direct neighbourhood of the contamination source. 
130 Environmental Health Risk

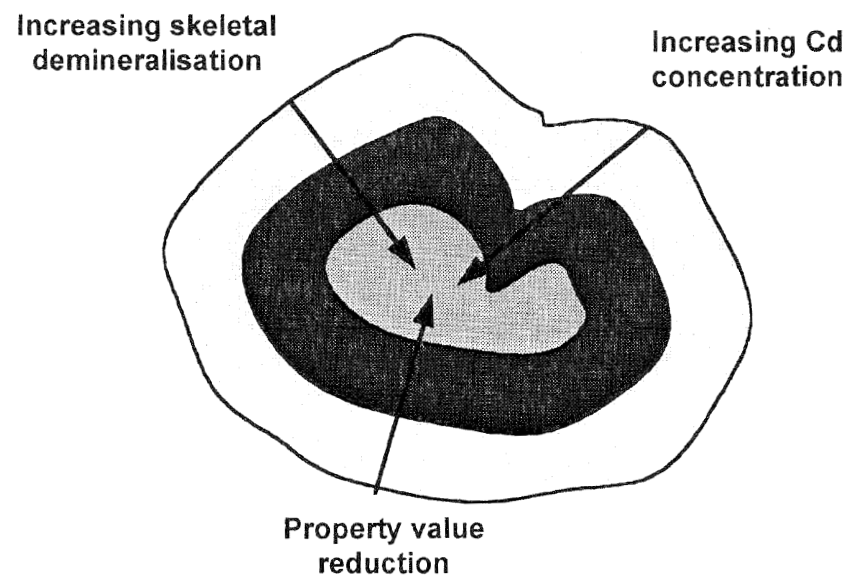

Figure 2. Link between Cd concentration levels, health effects and housing prices.

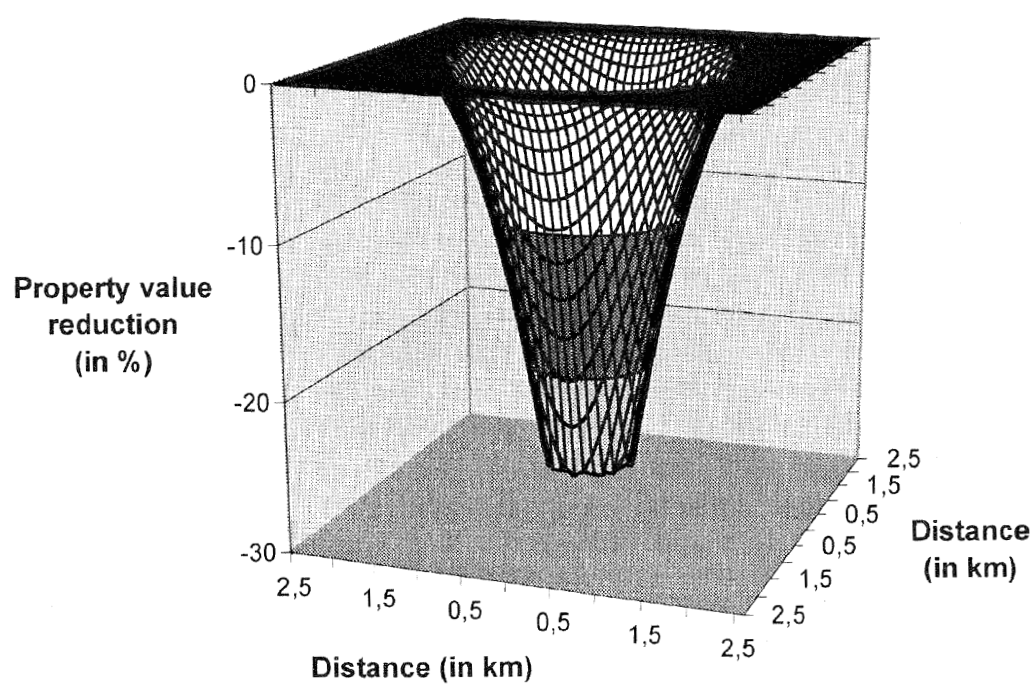

Figure 3. Stylized representation of property value reduction around the pollution area. 
The economic benefit results of the Lommel-Overpelt case study clearly differ from the meta-analysis of Brisson and Pearce [12]. The latter built their analysis mainly on American studies. First, the average reduction in housing value in the surroundings of the pollution source is markedly lower $(12.8 \%)$ then in the Lommel-Overpelt case (30\%). Second, the perceived negative impact of the contamination source in Lommel-Overpelt - as revealed in housing prices is limited to a distance of $2 \mathrm{~km}$. This is probably linked with the scarcity of residential space in Flanders in comparison with the United states. This shows the difficulty for European countries of relying on transferring the results of American studies. Europe definitely needs its own valuation studies in order to assess and monetize the risks from soil contamination (Thewys and Clauw [7]).

\section{Conclusion}

This paper has dealt with soil contamination risk. We have tried to establish the link between formal methods of risk assessment like site research (concentration levels of polluting substances), epidemiological studies (health effects of living in polluted areas) and the economic way of assessing risk (revelation in housing prices). The hedonic pricing method is a good tool for measuring social benefits stemming from soil reclamation programs in polluted areas. The growing concern for a clean environment makes it worthwhile to conduct economic valuation studies in a cost benefit framework, especially when the causality between health problems and a specific pollution source becomes more and more obvious. The Lommel-Overpelt case study shows evidence about the link between $\mathrm{Cd}$ concentration levels, adverse health effects as shown by an increasing skeletal demineralisation in the region and a nonlinear reduction in property value with the highest decrease in the immediate surroundings of the pollution source.

Finally, we want to pay attention to two important points about the application of the hedonic price method. First, it is absolutely necessary that the people living in the contaminated area are aware of the pollution. If there is no consciousness of what is going on, housing prices will not reflect the risks of living in the polluted area. Second, the link between the environmental good and the differentiated product (the house) may be weak. It can be difficult to disentangle what is really measured. Are we really measuring contamination effects or only the aesthetics of the neighbouring polluting factory? In this field, there is still a lot of research to do. The application of the hedonic price method should be conducted separately for people living in the neighbourhood of a polluting factory and for those living in the surroundings of a non-polluting company. Then, the results can be compared with each other. Nevertheless, the hedonic price method seems to be a most promising one since it is not only based on the concept of 'willingness to pay' for a clean environment, but this willingness to pay is also revealed in real market behaviour. 


\section{Environmental Health Risk}

\section{References}

[1] European Environment Agency, Europe's environment: the third assessment. Environmental Assessment Report, 10, 2003.

[2] Ferguson, C., Darmendrail, D., Freier, K., Jensen, B.K., Jensen, J., Kasamas, H., Urzelai, A., \& Vegter, J, Risk assessment for contaminated sites in Europe. Volume 1. Scientific Basis, LQM Press, Nottingham, 1998.

[3] Thewys, T., Kosten-batenanalyse en kosteneffectiviteitsanalyse in het kader van bodemsanering. Energie en Milieu, 3, pp. 116-119, 1998.

[4] Thayer, M., Albers, H. \& Rahmatian, M., The benefits of reducing exposure to waste disposal sites: a hedonic housing value approach. The Journal of Real Estate Research, 7(3), pp. 265-82, 1992.

[5] Kohlhase, J., The impact of toxic waste sites on housing values. Journal of Urban Economics, 30(1), pp.1-26, 1991.

[6] Rosen, S., Hedonic prices and implicit markets: product differentiation in pure competition. Journal of Political Economy, 82(1), pp. 34-55, 1974.

[7] Thewys, T.\& Clauw, F., Bodemsanering in een stakeholdersperspectief. Het meten van milieubaten via de hedonistische prijsmethode. Proc. of the $25^{\text {th }}$ Flemish Scientific Economic Congress (VWEC), eds. L. Peeters, P. Matthyssens \& L. Vereeck, Garant: Leuven, pp. 899-923, 2002.

[8] Lafère, J. \& Hens, L., Gezondheidsrisico's van wonen in de omgeving van een stortplaats of verbrandingsoven. Leefmilieu, 3, mei-juni, pp. 71-76, 2002.

[9] Dolk, H., Vrijheid, M., Armstrong, B., Abramsky, L., Bianchi, F., Garne, E., Nelen, V., Robert, E., Scott, J.E.S., Stone, D. \& Tenconi, R., Risk of congenital anomalies near hazardous-waste landfill sites in Europe: the EUROHAZCON study. The Lancet, 352, pp. 423-427, 1998.

[10] Benedetti, M., Lavarone, I. \& Comba, P., Cancer risk associated with residential proximity to industrial sites. Archives of Environmental Health, 56(4), pp. 342-349, 2001

[11] Nelen, V., Bevolkingsonderzoek voor lood Antwerpen, PIH, 2002.

[12] Gayer, T., Hamilton, J.T. \& Viscusi, W.K., Private values of risk tradeoffs at superfund sites: housing market evidence on learning about risk. The Review of Economics and Statistics, 82(3), pp. 439-451, 2000.

[13] Brisson, I. \& Pearce, D. Benefits transfer for disamenity from waste disposal. Waste Management Working Paper CSERGE, 6, 1995.

[14] Thewys, T., Draye, A-M.\& Kwanten, A., Economische baten van bodemsanering. Studie in opdracht van de Openbare Vlaamse Afvalstoffenmaatschappij, OVAM: Mechelen, pp. 75, 2000.

[15] Staessen, J., Roels, H., Emelianov, D., Kuznetsova, T., Thijs, L., Vangronsveld, J., \& Fagard, R., Environmental exposure to cadmium, forearm bone density, and risk of fractures: prospective population study. The Lancet, 353, pp. 1140-44, 1999. 